\title{
The Estimation of Residual Variance in Nonparametric Regression
}

\section{Pendugaan Varians Residual dalam Regresi Nonparametrik}

\author{
Abdul Wahab ${ }^{1}$, I Nyoman Budiantara ${ }^{2}$, Kartika Fitriasari ${ }^{3}$
}

\begin{abstract}
Given a nonparametric regression model

$$
Y_{i}=g\left(x_{i}\right)+\varepsilon_{i}, \quad i=1,2, \ldots, n,
$$

where $Y$ is a dependent variable, $x$ is an independent variable, $g$ is an unknown function and $\varepsilon$ is an error assumed to be an independent, identical, and is distributed with mean 0 and variance $\sigma^{2}$. In this research Rice estimator is used to determine the biased value of a residual variance estimator and the biased value of residual variance estimator of the Rice method. Using the Rice estimator, the Tong-Wang residual variance estimator is obtained. Based upon the data simulation by considering the exponential, arithmetical, and trigonometrical models, it is found that the MSE value of the Tong-Wang estimator tends to be less compared to those of the Rice estimator as well as the GSJ (Gasser, Sroka, and Jennen) estimator.
\end{abstract}

Key words: Nonparametric regression, Rice estimator, GSJ estimator, Tong-Wang estimator.

\begin{abstract}
ABSTRAK
Diberikan model regresi nonparametrik

$$
Y_{i}=g\left(x_{i}\right)+\varepsilon_{i}, \quad i=1,2, \ldots, n,
$$

dengan $Y$ adalah variabel dependen, $x$ variabel independen, $g$ fungsi yang tidak ditetapkan bentuknya dan $\varepsilon$ eror yang diasumsikan independen, identik dan berdistribusi dengan rataan 0 dan varians $\sigma^{2}$. Dalam penelitian ini digunakan penduga Rice untuk mendapatkan nilai bias penduga varians residual dan nilai bias penduga varians residual metode Rice. Dengan menggunakan penduga Rice diperoleh penduga varians residual Tong-Wang. Berdasarkan data simulasi dengan mempertimbangkan model eksponensial, aritmetika dan trigonometri diperoleh nilai MSE penduga Tong-Wang cenderung lebih kecil dibandingkan dengan penduga Rice dan penduga GSJ (Gasser, Sroka, dan Jennen).
\end{abstract}

Kata kunci: Regresi nonparametrik, Penduga Rice, penduga GSJ, penduga Tong-Wang.

\section{PENDAHULUAN}

Model regresi adalah suatu model yang menjelaskan hubungan antara suatu variabel independen $x$ dengan variabel dependen $Y$. Misalkan $\left(x_{i}, y_{i}\right), i=1,2, \ldots, n$, sampel acak berukuran $n$, dimana hubungan $x_{i}$ dan $y_{i}$ diasumsikan mengikuti model:

$$
Y_{i}=g\left(x_{i}\right)+\varepsilon_{i}
$$

dengan $g(x)$ merupakan kurva regresi, dan $\varepsilon_{i}$ eror yang diasumsikan independen, identik dan berdistribusi normal dengan rataan 0 dan varians $\sigma^{2}[1,3,4,13]$.

${ }^{1}$ Universitas Muslim Indonesia, ${ }^{2,3}$ Institut Teknologi Sepuluh Nopember Surabaya

Email:abdulwahab79@umi.ac.id ${ }^{l}$;__nyoman_b@statistika.its.ac.id ${ }^{2}$;

Kartika_f@statistika.its.ac.id ${ }^{3}$

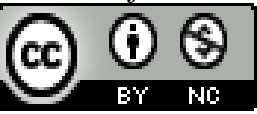

This work is licensed under a Creative Commons Attribution-NonCommercial 4.0 International License 


\section{Jurnal Matematika, Statistika E Komputasi}

Abdul Wahab, I Nyoman Budiantara, Kartika Fitriasari

Untuk menduga kurva $g$ dalam model (1.1), dapat dilakukan dengan dua jenis pendekatan, yaitu pendekatan regresi parametrik dan regresi nonparametrik. Pendekatan yang sering digunakan adalah model regresi parametrik mengasumsikan bentuk kurva $g$ tertentu dimana parameternya diduga dari suatu sampel. Menduga kurva $g$ sama dengan melakukan pendugaan parameter dalam fungsi regresi. Model regresi parametrik relatif lebih sederhana dibandingkan dengan model regresi nonparametrik. Jika model yang diasumsikan ini benar, maka pendugaan parametrik sangat efisien $[8,9,10]$.

Jika dalam model regresi (1.1) kurva $g$ tidak ditetapkan bentuknya dan $\varepsilon$ eror acak yang diasumsikan independen, identik, dan berdistribusi dengan rataan 0 dan varians $\sigma^{2}$, maka untuk menduga $g$ dapat digunakan regresi nonparametrik.

yaitu:

Penduga $\sigma^{2}$ dapat dinyatakan dalam bentuk kuadratik dari vektor respon $\boldsymbol{y}=\left(y_{1}, y_{2}, \ldots, y_{n}\right)^{\prime}$

$$
\hat{\sigma}_{D}^{2}=\frac{\mathbf{y}^{\prime} \mathbf{D} \mathbf{y}}{\operatorname{tr}(\mathbf{D})}
$$

dengan $\mathbf{D}=(\mathbf{I}-\mathbf{A})^{\prime}(\mathbf{I}-\mathbf{A})$, dimana $\mathbf{A}$ suatu matriks tertentu [2].

Beberapa penduga untuk $\sigma^{2}$ telah dikembangkan oleh banyak penulis, seperti penduga Rice [11] yang mengajukan penduga difference-based order pertama yang dikenal sebagai penduga $\mathrm{R}$. Gasser, Sroka dan Jennen (GSJ) [5] mengajukan penduga difference-based order kedua yang dikenal sebagai penduga GSJ. Dari penduga-penduga ini tidak ada satu pun penduga tersebut mencapai tingkat asimtotik yang optimal berdasarkan mean squared eror (MSE) [6, 14].

Dari uraian di atas, permasalahan yang akan disajikan dalam penelitian ini adalah (1) bagaimana menentukan nilai bias penduga varians residual metode Rice?, (2) bagaimana menentukan penduga varians residual metode Tong-Wang?. (3) bagaimana kebaikan penduga Tong-Wang, Rice dan GSJ berdasarkan data simulasi?.

\section{KAJIAN PUSTAKA}

\section{Penduga Difference Based}

Penduga difference-based merupakan penduga yang menggunakan beda (difference) untuk merubah trend dalam fungsi rataan, penduga ini berasal dari gagasan analisis runtun waktu yang tidak memerlukan dugaan fungsi rataan.

Berikut ini diberikan beberapa penduga difference-based diantaranya penduga Rice (Rice, 1984), penduga Gasser, Sroka, dan Jennen [5] dan penduga Tong-Wang [15]).

Penduga Rice merupakan penduga difference-based dengan order pertama, yang biasa dikenal dengan simbol $\hat{\sigma}_{R}^{2}$.

$$
\hat{\sigma}_{R}^{2}=\frac{1}{2(n-1)} \sum_{i=2}^{n}\left(Y_{i}-Y_{i-1}\right)^{2}
$$

Penduga Gasser, Sroka dan Jennen merupakan penduga difference-based order kedua, yang lebih dikenal sebagai penduga GSJ dengan simbol $\hat{\sigma}_{G S J}^{2}$.

$$
\hat{\sigma}_{G S J}^{2}=\frac{2}{3(n-2)} \sum_{i=2}^{n-1}\left(\frac{1}{2} Y_{i-1}-Y_{i}+\frac{1}{2} Y_{i+1}\right)^{2},
$$

Penduga Tong-Wang merupakan penduga difference-based yang dapat diaplikasikan pada model regresi nonparametrik dengan fungsi multivariat. Penduga tersebut telah dikembangkan pada pemilihan bandwidth dan telah menunjukkan bahwa penduga tersebut mencapai tingkat asimtotik yang optimal berdasarkan mean square error (MSE). Penduga Tong-Wang diturunkan dari penduga Rice yang lebih dikenal sebagai penduga TW dengan simbol $\hat{\sigma}_{T W}^{2}[15]$. 


\section{Jurnal Matematika, Statistika E Komputasi}

\section{Abdul Wahab, I Nyoman Budiantara, Kartika Fitriasari}

\section{HASIL DAN PEMBAHASAN}

\subsection{Nilai Bias Penduga Varians Residual Metode Rice}

Berdasarkan definisi penduga Rice pada persamaan (2.1) dan model regresi pada persamaan (1.1) dengan $g(x)$ mempunyai turunan pertama yang terbatas, maka langkah awal yang digunakan oleh metode Rice adalah menentukan nilai harapan (expectation) dari penduga Rice sebagai berikut:

$$
\begin{aligned}
E\left(\hat{\sigma}_{R}^{2}\right) & =\frac{1}{2(n-1)} \sum_{i=2}^{n} E\left(Y_{i}-Y_{i-1}\right)^{2} \\
& =\frac{1}{2(n-1)} \sum_{i=2}^{n}\left(\left(g\left(x_{i}\right)\right)^{2}+\sigma^{2}-2\left(g\left(x_{i}\right)\right)\left(g\left(x_{i-1}\right)\right)+\left(g\left(x_{i-1}\right)\right)^{2}+\sigma^{2}\right) \\
& =\sigma^{2}+\frac{1}{2(n-1)} \sum_{i=2}^{n}\left(g\left(x_{i}\right)-g\left(x_{i-1}\right)\right)^{2}
\end{aligned}
$$

Ini mengindikasikan bahwa penduga Rice selalu bias positif. Mengingat $g$ mempunyai turunan pertama yang terbatas, maka persamaan (3.1) dapat diuraikan dengan menggunakan penderetan Taylor. Dari definisi deret Taylor yang dikembangkan disekitar titik $x=z_{i}$ diperoleh:

$$
g\left(x_{i}\right)-g\left(x_{i-1}\right)=\left(x_{i}-x_{i-1}\right) g^{\prime}\left(z_{i}\right)+\left(x_{i}-x_{i-1}\right) \sum_{n=2}^{\infty} \sum_{j=0}^{n-1} \frac{\left(\left(x_{i}-z_{i}\right)^{n-1-j}\left(x_{i-1}-z_{i}\right)^{j}\right)}{n !} g^{(n)}\left(z_{i}\right)
$$

Berdasarkan definisi little-o, persamaan $(3,2)$ dapat ditulis seperti berikut:

$$
\begin{aligned}
& g\left(x_{i}\right)-g\left(x_{i-1}\right)=\left(x_{i}-x_{i-1}\right) g^{\prime}\left(z_{i}\right)+o\left(x_{i}-x_{i-1}\right) \\
& g\left(x_{i}\right)-g\left(x_{i-1}\right)=\frac{1}{n} g^{\prime}\left(z_{i}\right)+o\left(\frac{1}{n}\right) ; \quad x_{i-1}<z_{i}<x_{i}
\end{aligned}
$$

Sehingga persamaan (3.1) menjadi:

$$
\begin{aligned}
E\left(\hat{\sigma}_{R}^{2}\right) & =\sigma^{2}+\frac{1}{2(n-1)} \sum_{i=2}^{n}\left(\frac{1}{n} g^{\prime}\left(x_{i}\right)+o\left(\frac{1}{n}\right)\right)^{2} \\
& =\sigma^{2}+\frac{1}{n^{2}} \frac{1}{2} \int_{0}^{1}\left(g^{\prime}(x)\right)^{2} d x+o\left(\frac{1}{n^{2}}\right) \\
& =\sigma^{2}+\frac{1}{n^{2}} J+o\left(\frac{1}{n^{2}}\right)
\end{aligned}
$$

dimana $J=\frac{1}{2} \int_{0}^{1} g^{\prime}(x)^{2} d x[12]$.

Selanjutnya didefinisikan penduga Rice pada lag- $k$ :

$$
\hat{\sigma}_{R}^{2}(k)=\frac{1}{2(n-k)} \sum_{i=k+1}^{n} E\left(Y_{i}-Y_{i-k}\right)^{2}
$$

kemudian diuraikan serupa seperti persamaan (3.1) dengan menentukan nilai harapan penduga Rice pada lag- $k$ :

$$
\begin{aligned}
E\left(\hat{\sigma}_{R}^{2}(k)\right) & =\frac{1}{2(n-k)} \sum_{i=k+1}^{n} E\left(Y_{i}-Y_{i-k}\right)^{2} \\
& =\sigma^{2}+\frac{1}{2(n-k)} \sum_{i=k+1}^{n}\left(g\left(x_{i}\right)-g\left(x_{i-k}\right)\right)^{2}
\end{aligned}
$$

Mengingat $g$ mempunyai turunan pertama yang terbatas, maka serupa dengan persamaan (3.3) yang diuraikan dengan menggunakan penderetan Taylor diperoleh: 


\section{Jurnal Matematika, Statistika \& Komputasi}

\section{Abdul Wahab, I Nyoman Budiantara, Kartika Fitriasari}

$$
\begin{gathered}
g\left(x_{i}\right)-g\left(x_{i-k}\right)=\left(x_{i}-x_{i-k}\right) g^{\prime}\left(z_{i}\right)+\left(x_{i}-x_{i-k}\right) \sum_{n=2}^{\infty} \sum_{j=0}^{n-1} \frac{\left(\left(x_{i}-z_{i}\right)^{n-1-j}\left(x_{i-k}-z_{i}\right)^{j}\right)}{n !} g^{(n)}\left(z_{i}\right) \\
g\left(x_{i}\right)-g\left(x_{i-k}\right)=\left(x_{i}-x_{i-k}\right) g^{\prime}\left(z_{i}\right)+\left(x_{i}-x_{i-k}\right) \sum_{n=2}^{\infty} \frac{g^{(n)}\left(z_{i}\right)}{n !}\left[\left(x_{i}-z_{i}\right)^{n-1}+\right. \\
\left.\left(x_{i}-z_{i}\right)^{n-2}\left(x_{i-k}-z_{i}\right)+\left(x_{i}-z_{i}\right)^{n-3}\left(x_{i-k}-z_{i}\right)^{2}+\cdots+\left(x_{i-k}-z_{i}\right)^{n-1}\right] \\
g\left(x_{i}\right)-g\left(x_{i-k}\right)=\left(x_{i}-x_{i-k}\right) g^{\prime}\left(z_{i}\right)+\left(x_{i}-x_{i-k}\right)^{2} \sum_{n=2}^{\infty} \frac{g^{(n)}\left(z_{i}\right)}{n !}\left[\left(x_{i}-z_{i}\right)^{n-2}+\right. \\
\left.\frac{2\left(x_{i}-z_{i}\right)^{n-2}\left(x_{i-k}-z_{i}\right)+\left(x_{i}-z_{i}\right)^{n-3}\left(x_{i-k}-z_{i}\right)^{2}+\cdots+\left(x_{i-k}-z_{i}\right)^{n-1}}{\left(x_{i}-x_{i-k}\right)}\right]
\end{gathered}
$$

Berdasarkan definisi big-oh dapat ditulis seperti berikut:

$$
\begin{aligned}
& g\left(x_{i}\right)-g\left(x_{i-k}\right)=\left(x_{i}-x_{i-k}\right) g^{\prime}\left(z_{i}\right)+O\left(x_{i}-x_{i-k}\right)^{2} \\
& g\left(x_{i}\right)-g\left(x_{i-k}\right)=\frac{k}{n} g^{\prime}\left(z_{i}\right)+O\left(\frac{k^{2}}{n^{2}}\right) ; \quad x_{i-1}<z_{i}<x_{i}
\end{aligned}
$$

Sehingga persamaan (3.5) menjadi:

$$
\begin{aligned}
E\left(\hat{\sigma}_{R}^{2}\right) & =\sigma^{2}+\frac{1}{2(n-k)} \sum_{i=k+1}^{n}\left(\frac{k}{n} g^{\prime}\left(x_{i}\right)+O\left(\frac{k^{2}}{n^{2}}\right)\right)^{2} \\
& =\sigma^{2}+\frac{1}{2} \frac{k^{2}}{n^{2}} \frac{1}{(n-k)}\left((n-k) \int_{0}^{1}\left(g^{\prime}(x)\right)^{2} d x\right)+O\left(\frac{k^{3}}{n^{3}}\right) \\
& =\sigma^{2}+\frac{k^{2}}{n^{2}} \frac{1}{2} \int_{0}^{1}\left(g^{\prime}(x)\right)^{2} d x+O\left(\frac{k^{3}}{n^{3}}\right)
\end{aligned}
$$

Dengan memisalkan $J=\frac{1}{2} \int_{0}^{1}\left(g^{\prime}(x)\right)^{2} d x$ maka diperoleh:

$$
\begin{aligned}
E\left(\hat{\sigma}_{R}^{2}\right)= & \sigma^{2}+\frac{k^{2}}{n^{2}} J+O\left(\frac{k^{3}}{n^{3}}\right) \\
& =\sigma^{2}+J d_{k}+O\left(\frac{k^{3}}{n^{3}}\right)
\end{aligned}
$$

dimana $J d_{k}+O\left(\frac{k^{3}}{n^{3}}\right)$ merupakan nilai bias penduga varians residual metode Rice dengan $d_{k}=\frac{k^{2}}{n^{2}}$

\subsection{Penduga Varians Residual Metode Tong-Wang}

Pada bagian ini akan dikaji mengenai pendugaan varians berdasarkan metode Tong-Wang dimana erat kaitannya dengan metode Rice karena metode Tong-Wang menggunakan penduga Rice. 


\section{Jurnal Matematika, Statistika E Komputasi}

\section{Abdul Wahab, I Nyoman Budiantara, Kartika Fitriasari}

Langkah awal yang digunakan oleh metode Tong-Wang adalah dengan terlebih dahulu mendefinisikan $d_{k}$ dan $s_{k}$ sebagai berikut:

$$
\begin{aligned}
& d_{k}=\frac{k^{2}}{n^{2}} \text { dan } \\
& s_{k}=\frac{1}{2(n-k)} \sum_{i=k+1}^{n}\left(Y_{i}-Y_{i-k}\right)^{2}, \quad k=1,2, \ldots, m
\end{aligned}
$$

Selanjutnya diberikan data berpasangan $\left(d_{k}, s_{k}\right), k=1,2, \ldots, m$. Tong dan Wang membuat model regresi:

$$
s_{k}=\beta_{0}+\beta_{1} d_{k}+\varepsilon_{k}, k=1,2, \ldots, m .
$$

Parameter $\beta_{0}$ dan $\beta_{1}$ di duga dengan menggunakan metode kuadrat terkecil terbobot dengan bobot $w_{k}=\frac{n-k}{N}$, dimana $N=\sum_{k=1}^{m}(n-k)=n m--\frac{m(m+1)}{2}$ yaitu:

$$
\boldsymbol{Q}\left(\beta_{0}, \beta_{1}\right)=\sum_{k=1}^{m} w_{k} \varepsilon_{k}^{2}=\sum_{k=1}^{m} w_{k}\left(s_{k}-\beta_{0}-\beta_{1} d_{k}\right)^{2}
$$

Dengan menurunkan secara parsial persamaan (3.8) terhadap $\beta_{0}$ dan $\beta_{1}$ kemudian menyamakan hasil penurunan dengan nol diperoleh:

$$
\begin{aligned}
& \frac{\partial\left(\boldsymbol{Q}\left(\beta_{\boldsymbol{0}}, \beta_{1}\right)\right)}{\partial \beta_{0}}=-2 \sum_{k=1}^{m} w_{k}\left(s_{k}-\beta_{0}-\beta_{1} d_{k}\right) \\
& \frac{\partial\left(\boldsymbol{Q}\left(\beta_{\boldsymbol{0}}, \beta_{1}\right)\right)}{\partial \beta_{1}}=-2 \sum_{k=1}^{m} w_{k} d_{k}\left(s_{k}-\beta_{0}-\beta_{1} d_{k}\right)
\end{aligned}
$$

Sehingga nilai dugaan $\hat{\beta}_{0}$ dan $\hat{\beta}_{1}$ diperoleh dari sistem persamaan:

$$
\begin{aligned}
& \sum_{k=1}^{m} w_{k} s_{k}-\hat{\beta}_{0} \sum_{k=1}^{m} w_{k}-\hat{\beta}_{1} \sum_{k=1}^{m} w_{k} d_{k}=0 \\
& \sum_{k=1}^{m} w_{k} s_{k} d_{k}-\hat{\beta}_{0} \sum_{k=1}^{m} w_{k} d_{k}-\hat{\beta}_{1} \sum_{k=1}^{m} w_{k} d_{k}^{2}=0
\end{aligned}
$$

Dengan memisalkan $s_{w}=\sum_{k=1}^{m} w_{k} s_{k}$ dan $d_{w}=\sum_{k=1}^{m} w_{k} d_{k}$, maka persamaan (3.10) dan persamaan (3.11) memberikan

$$
\begin{aligned}
& s_{w}-\hat{\beta}_{0} \sum_{k=1}^{m} w_{k}-\hat{\beta}_{1} d_{w}=0 \\
& \sum_{k=1}^{m} w_{k} s_{k} d_{k}-\hat{\beta}_{0} d_{w}-\hat{\beta}_{1} \sum_{k=1}^{m} w_{k} d_{k}^{2}=0
\end{aligned}
$$

Dengan menyederhanakan persamaan (3.12) dan persamaan (3.13), dan memperhatikan $\sum_{k=1}^{m} w_{k}=1$ diperoleh $\hat{\beta}_{0}$ dan $\hat{\beta}_{1}$ sebagai berikut

$$
\begin{aligned}
& s_{w}-\hat{\beta}_{0}-\hat{\beta}_{1} d_{w}=0 \\
& \hat{\beta}_{0}=s_{w}-\hat{\beta}_{1} d_{w}
\end{aligned}
$$

Substitusi persamaan (3.13) ke (3.12) memberikan

$$
\sum_{k=1}^{m} w_{k} s_{k}\left(d_{k}-d_{w}\right)-\hat{\beta}_{1} \sum_{k=1}^{m} w_{k}\left(d_{k}-d_{w}\right)^{2}=0
$$




\section{Jurnal Matematika, Statistika \& Komputasi}

\section{Abdul Wahab, I Nyoman Budiantara, Kartika Fitriasari}

$$
\hat{\beta}_{1}=\frac{\sum_{k=1}^{m} w_{k} s_{k}\left(d_{k}-d_{w}\right)}{\sum_{k=1}^{m} w_{k}\left(d_{k}-d_{w}\right)^{2}}
$$

Penduga varians residual metode Tong-Wang $\left(\hat{\sigma}_{T w}^{2}\right)$ ditentukan berdasarkan persamaan $\hat{\sigma}^{2}=\hat{\beta}_{0}$, maka $\hat{\sigma}^{2}=\hat{\beta}_{0}=s_{w}-\hat{\beta}_{1} d_{w}$ atau dapat ditulis dalam bentuk:

$$
\hat{\sigma}_{T W}^{2}=s_{w}-\frac{\sum_{k=1}^{m} w_{k} s_{k}\left(d_{k}-d_{w}\right)}{\sum_{k=1}^{m} w_{k}\left(d_{k}-d_{w}\right)^{2}} d_{w}
$$

\subsection{Studi Simulasi}

Dalam studi simulasi ini digunakan tiga model yang berbeda yaitu model eksponensial, model aritmetika dan model trigonometri yang dapat menggambarkan bahwa penduga Tong-Wang lebih baik daripada penduga Rice dan GSJ dengan menggunakan kriteria nilai MSE [8].

Diberikan model pada persamaan (1.1) dengan $g\left(x_{i}\right)$ merupakan kurva regresi, dan $\varepsilon_{i}$ adalah eror yang diasumsikan independen, identik dan berdistribusi normal dengan rataan 0 dan varians $\sigma^{2}$. Pertama-tama eror $\left(\varepsilon_{i}\right)$ dibangkitkan dari distribusi normal dengan rataan 0 dan varians $\sigma^{2}$. Dalam simulasi ini digunakan standar deviasi $\sigma=0,1,0,2,0,4$, dan ukuran sampel $n=50$, 100, 200. Selanjutnya diberikan model eksponensial fungsi $g(x)=5 e^{-5 x}$, model aritmetika fungsi $g(x)=\sqrt{5 x}$ dan trigonometri fungsi $g(x)=5 \sin (\pi x)$ dengan $x_{i}=\frac{i}{n}, i=1,2, \ldots, n$.

Untuk setiap model simulasi dihitung masing-masing penduga Rice, GSJ, dan Tong-Wang serta dilakukan replikasi sebanyak 50 kali untuk mendapatkan hasil yang lebih baik dan menghitung nilai MSE masing-masing penduga. Dalam simulasi ini penduga Tong-Wang digunakan $m=10$ sehingga penduga Tong-Wang dapat ditulis seperti berikut:

$$
\hat{\sigma}_{T W}^{2}=s_{w}-\frac{\sum_{k=1}^{10} w_{k} s_{k}\left(d_{k}-d_{w}\right)}{\sum_{k=1}^{10} w_{k}\left(d_{k}-d_{w}\right)^{2}} d_{w}, \quad k=1,2, \ldots, 10 .
$$

Berikut ini di berikan hasil simulasi dari ketiga model yang telah ditetapkan sebelumnya.

\subsubsection{Model Eksponensial}

Model eksponensial diwakili model fungsi $g(x)=5 e^{-5 x}$. Penduga Tong-Wang cenderung menghasilkan nilai MSE lebih kecil dibandingkan dengan penduga Rice dan GSJ. Nilainilai MSE ini diperlihatkan pada Tabel 1 berikut:

Tabel 3.1. Nilai MSE penduga Rice, GSJ dan Tong-Wang model eksponensial

\begin{tabular}{|c|c|c|c|c|}
\hline \multirow{2}{*}{$n$} & $\sigma$ & $M S E_{\sigma_{R}^{2}}$ & $M S E_{\sigma_{G S J}^{2}}$ & $M S E_{\sigma_{T W}^{2}}$ \\
\hline \multirow{3}{*}{50} & 0,1 & 0,00630427 & 0,00807704 & 0,00314443 \\
\cline { 2 - 5 } & 0,2 & 0,0223638 & 0,0257054 & 0,0157560 \\
\cline { 2 - 5 } & 0,4 & 0,0564276 & 0,0622543 & 0,0452205 \\
\hline
\end{tabular}




\section{Jurnal Matematika, Statistika \& Komputasi} Abdul Wahab, I Nyoman Budiantara, Kartika Fitriasari

\begin{tabular}{|c|c|c|c|c|}
\hline \multirow{3}{*}{100} & 0,1 & 0,00759212 & 0,00811573 & 0,00693168 \\
\cline { 2 - 5 } & 0,2 & 0,0241701 & 0,0250514 & 0,0232366 \\
\cline { 2 - 5 } & 0,4 & 0,0550265 & 0,0566955 & 0,0541513 \\
\hline \multirow{3}{*}{200} & 0,1 & 0,00793990 & 0,00806621 & 0,00792122 \\
\cline { 2 - 5 } & 0,2 & 0,0254684 & 0,0258060 & 0,0253022 \\
\cline { 2 - 5 } & 0,4 & 0,0587375 & 0,0597955 & 0,0572666 \\
\hline
\end{tabular}

Perbandingan dari semua nilai MSE masing-masing penduga dengan memperhatikan semua kasus, penduga Tong-Wang mempunyai nilai MSE cenderung lebih kecil dibandingkan dengan penduga Rice dan GSJ. Secara umum nilai MSE penduga Tong-Wang cenderung lebih kecil dibandingkan dengan nilai MSE penduga Rice dan GSJ.

\subsubsection{Model Aritmetika}

Model aritmetika diwakili model fungsi $g(x)=\sqrt{5 x}$. Penduga Tong-Wang cenderung menghasilkan nilai MSE lebih kecil dibandingkan dengan penduga Rice dan GSJ. Nilai-nilai MSE ini diperlihatkan pada Tabel 3.2 berikut:

Tabel 3.2. Nilai MSE penduga Rice, GSJ dan Tong-Wang model aritmetika

\begin{tabular}{|c|c|c|c|c|}
\hline$n$ & $\sigma$ & $\hat{\sigma}_{R}^{2}$ & $\hat{\sigma}_{G S J}^{2}$ & $\hat{\sigma}_{T W}^{2}$ \\
\hline \multirow{3}{*}{50} & 0,1 & 0,00795866 & 0,00815830 & 0,00784188 \\
\cline { 2 - 5 } & 0,2 & 0,0251320 & 0,0254710 & 0,0248760 \\
\cline { 2 - 5 } & 0,4 & 0,0596900 & 0,0611103 & 0,0584554 \\
\hline \multirow{3}{*}{100} & 0,1 & 0,00807126 & 0,00811456 & 0,00804272 \\
\cline { 2 - 5 } & 0,2 & 0,0255882 & 0,0259366 & 0,0252618 \\
\cline { 2 - 5 } & 0,4 & 0,0609150 & 0,0616366 & 0,0588003 \\
\hline \multirow{3}{*}{200} & 0,1 & 0,00805793 & 0,00807134 & 0,00804650 \\
\cline { 2 - 5 } & 0,2 & 0,0255550 & 0,0256193 & 0,0255159 \\
\cline { 2 - 5 } & 0,4 & 0,0571781 & 0,0575031 & 0,0570076 \\
\hline
\end{tabular}

Perbandingan komparatif dari semua nilai MSE masing-masing penduga dengan memperhatikan semua kasus, penduga Tong-Wang mempunyai nilai MSE cenderung lebih kecil dibandingkan dengan penduga Rice dan GSJ. Secara umum nilai MSE penduga Tong-Wang cenderung lebih kecil dibandingkan dengan nilai MSE penduga Rice dan GSJ.

\subsubsection{Model Trigonometri}

Model trigonometri diwakili model fungsi $g(x)=5 \sin (\pi x)$. Penduga Tong-Wang cenderung menghasilkan nilai MSE lebih kecil dibandingkan dengan penduga Rice dan GSJ. Nilainilai MSE ini diperlihatkan pada Tabel 3.3 berikut:

Tabel 3.3. Nilai MSE penduga Rice, GSJ dan Tong-Wang model trigonometri

\begin{tabular}{|c|c|c|c|c|}
\hline$n$ & $\sigma$ & $M S E_{\sigma_{R}^{2}}$ & $M S E_{\sigma_{G S J}^{2}}$ & $M S E_{\sigma_{T W}^{2}}$ \\
\hline \multirow{2}{*}{50} & 0,1 & 0,00442043 & 0,00817706 & 0,00146124 \\
\cline { 2 - 5 } & 0,2 & 0,0188804 & 0,0260000 & 0,0119870 \\
\cline { 2 - 5 } & 0,4 & 0,0509689 & 0,0630291 & 0,0375662 \\
\hline \multirow{2}{*}{100} & 0,1 & 0,00707648 & 0,00814413 & 0,00705189 \\
\cline { 2 - 5 } & 0,2 & 0,0237481 & 0,0257312 & 0,0236087 \\
\cline { 2 - 5 } & 0,4 & 0,0561481 & 0,0598329 & 0,0555613 \\
\hline \multirow{2}{*}{200} & 0,1 & 0,00777726 & 0,00803215 & 0,00796694 \\
\cline { 2 - 5 } & 0,2 & 0,0250527 & 0,0255649 & 0,0253171 \\
\hline
\end{tabular}




\section{Jurnal Matematika, Statistika \& Komputasi} Abdul Wahab, I Nyoman Budiantara, Kartika Fitriasari

\begin{tabular}{|l|l|l|l|l|}
\hline & 0.4 & 0.0604095 & 0.0620450 & 0.0583181 \\
\hline
\end{tabular}

Perbandingan dari semua nilai MSE masing-masing penduga, penduga Tong-Wang mempunyai nilai MSE cenderung lebih kecil dari penduga GSJ dan Rice kecuali untuk dua kasus yaitu $(n, \sigma)=(200,0,1)$ dan $(200,0,2)$ dimana nilai MSE penduga Rice lebih kecil dibandingkan dengan penduga GSJ dan Tong-Wang. Secara umum nilai MSE penduga Tong-Wang cenderung lebih kecil dibandingkan dengan nilai MSE penduga Rice dan GSJ.

\section{SIMPULAN}

Berdasarkan hasil dan pembahasan yang telah diuraikan sebelumnya, maka dapat ditarik beberapa simpulan antara lain:

Penduga varians residual metode Rice merupakan penduga bias dengan nilai biasnya adalah $\theta=J d_{k}+O\left(\frac{k^{3}}{n^{3}}\right)$, dengan $J=\frac{1}{2} \int_{0}^{1}\left(g^{\prime}(x)\right) d x$ dan $d_{k}=\frac{k^{2}}{n^{2}}, k=1,2, \ldots, m$.

Penduga varians residual metode Tong-Wang diberikan oleh

$$
\hat{\sigma}_{T W}^{2}=s_{w}-\frac{\sum_{k=1}^{m} w_{k} s_{k}\left(d_{k}-d_{w}\right)}{\sum_{k=1}^{m} w_{k}\left(d_{k}-d_{w}\right)^{2}} d_{w}
$$

$$
\begin{gathered}
\text { dengan } w_{k}=\frac{n-k}{N}, N=\sum_{k=1}^{m}(n-k), d_{w}=\sum_{k=1}^{m} w_{k} d_{k}, s_{w}=\sum_{k=1}^{m} w_{k} s_{k} \text { dan } \\
s_{k}=\frac{1}{2(n-k)} \sum_{i=k+1}^{n}\left(Y_{i}-Y_{i-k}\right)^{2}, k=1,2, \ldots, m .
\end{gathered}
$$

Hasil simulasi dengan standar deviasi $\sigma=0,1,0,2,0,4$, dan ukuran sampel $n=50,100,200$, untuk fungsi eksponensial, fungsi aritmetika dan fungsi trigonometri, penduga Tong-Wang cenderung lebih baik, karena mempunyai nilai MSE yang cenderung lebih kecil dibandingkan dengan penduga Rice dan penduga GSJ.

\section{DAFTAR PUSTAKA}

[1] Buckley, M. J., Eagleson, G. K., \& Silverman, B. W. 1988. The Estimation of Residual Variance in Nonparametric Regression. Biometrika, 75(2), 189. https://doi.org/10.2307/2336166

[2] Dette, H., Munk, A., \& Wagner, T. 1998. Estimating the variance in nonparametric regression what is a reasonable choice? Journal of the Royal Statistical Society B, 60(4), 751-764.

[3] Drygas, H. 1972. The estimation of residual variance in regression analysis. Mathematische Operationsforschung Und Statistik, 3(5), 373-388. https://doi.org/10.1080/02331887208801094

[4] Evans, D., \& Jones, A. J. 2008. Non-parametric estimation of residual moments and covariance. Proceedings of the Royal Society A: Mathematical, Physical and Engineering Sciences, 464(2099), 2831-2846. https://doi.org/10.1098/rspa.2007.0195

[5] GASSER, T., SROKA, L., \& JENNEN-STEINMETZ, C. 1986. Residual variance and residual pattern in nonlinear regression. Biometrika, 73(3), 625-633. https://doi.org/10.1093/biomet/73.3.625

[6] Liitiäinen, E., Verleysen, M., Corona, F., \& Lendasse, A. 2009. Residual variance estimation in machine learning. Neurocomputing, 72(16-18), 3692-3703.

https://doi.org/10.1016/j.neucom.2009.07.004 


\section{Jurnal Matematika, Statistika \& Komputasi}

\section{Abdul Wahab, I Nyoman Budiantara, Kartika Fitriasari}

[8] Mendez, G., \& Lohr, S. 2011. Estimating residual variance in random forest regression. Computational Statistics \& Data Analysis, 55(11), 2937-2950. https://doi.org/10.1016/j.csda.2011.04.022

[9] Octavanny, M. A. D., Budiantara, I. N., Kuswanto, H., \& Rahmawati, D. P. 2020. Nonparametric Regression Model for Longitudinal Data with Mixed Truncated Spline and Fourier Series. Abstract and Applied Analysis, 2020, 1-11. https://doi.org/10.1155/2020/4710745

[10] Purnomo, J., Budiantara, I., \& Fitriasari, K. 2008. Weight estimation using generalized moving average. IPTEK The Journal for Techhnology and Science, 19(4).

[11] Rice, J. 1984. Bandwidth Choice for Nonparametric Regression. The Annals of Statistics, 12(4), 1215-1230. https://doi.org/10.1214/aos/1176346788

[12] Rohatgi, V. . 1976. An Introduction to probability theory and mathematical statistics. USA: john Wiley \& Sons Inc.

[13] Serfling, R. J. 1980. Approximation theorems of mathematical statistics. USA: john Wiley \& Sons Inc.

[14] Spokoiny, V. 2002. Variance Estimation for High-Dimensional Regression Models. Journal of Multivariate Analysis, 82(1), 111-133. https://doi.org/10.1006/jmva.2001.2023

[15] Tong, T., \& Wang, Y. 2005. Estimating residual variance in nonparametric regression using least squares. Biometrika, 92(4), 821-830. https://doi.org/10.1093/biomet/92.4.821 